\title{
HOW SHOULD WE EVALUATE AND USE EVIDENCE TO IMPROVE POPULATION ORAL HEALTH?
}

Paul R Brocklehurst. BDS, BSc (Hons), MDPH, PhD, FFGDP, FDS RCS (Eng).

Professor of Health Services Research, Normal Site, Bangor University, Bangor. p.brocklehurst@bangor.ac.uk +44 1248383218

Sarah R Baker. BSc, PhD, AFBPsS. Professor of Psychology as applied to Dentistry, The School of Clinical Dentistry, University of Sheffield, Sheffield.

s.r.baker@sheffield.ac.uk +44 1142159312

Stefan Listl. DDS, PhD. Professor of Quality and Safety of Oral Health Care, Faculty of Medical Sciences, Radboud University, The Netherlands.

stefan.listl@radboudumc.n! +31243616161

Marco A Peres. BDS, MSc, PhD. Professor of Population Oral Health, Adelaide

Dental School, The University of Adelaide, Adelaide, South Australia.

marco.peres@adelaide.edu.au +61 883135438

Georgios Tsakos. BDS, MSc, PhD, FHEA. Reader in Dental Public Health, Department of Epidemiology and Public Health, University College, 1-19 Torrington Place, London g.tsakos@ucl.ac.uk+44 2076795614

Jo Rycroft-Malone. RN, BSc, MSc, PhD. Professor of Health Services Research, Main Arts Building, Bangor University, Bangor. i.rycroft-malone@bangor.ac.uk +44 1248383119 


\section{Background}

Half of the world's population suffers from untreated oral conditions, affecting a total of 3.5 billion people in 2015; 2.5 billion people were affected by untreated caries in permanent teeth, 573 million children by untreated caries in deciduous teeth, 538 million people by severe periodontal disease, and 276 million people were affected by total tooth loss. ${ }^{1}$ Dental diseases produce large societal costs, both in terms of treatment costs and losses to productivity; for the EU-28 countries, dental diseases led to treatment costs of $\$ 100$ billion (92 billion EUR) and productivity losses of $\$ 57$ billion (52 billion EUR) in 2015. ${ }^{2,3}$

Given this, generating and implementing evidence-based policy is an important aim for many public-funded health systems. ${ }^{4}$ In dentistry, this is based on the assumption that evidence-based healthcare increases the efficiency and effectiveness of interventions to improve oral health at a population level. ${ }^{5}$ However, it is increasingly recognised that a linear or 'logic model' that links the generation of research evidence with its use, is overly simplistic. ${ }^{6}$ This paper challenges an uncritical interpretation of the evidence-based paradigm and explores approaches to the evaluation of complex interventions and how they can be embedded into policy and practice to improve oral health at a population level.

\section{The challenge of generating the evidence}

The process of generating robust research evidence has traditionally relied on randomised controlled clinical trials (RCTs) to empirically evaluate interventions. ${ }^{7}$ Any observed effect is pooled statistically and the evidence is then synthesised to create evidence-based policies. ${ }^{8}$ Research evidence is then either 'pushed' from the research community (in guidelines or evidence summaries), or 'pulled' by clinicians who are seeking evidence-based approaches to inform their approach to care. However, there are a number of inherent difficulties with a push-pull assumption when the intervention is complex, ${ }^{9}$ or where it attempts to "introduce new, or modify existing, patterns of collective action in health care or some other formal organisational setting". ${ }^{10}$

The first problem is that the quality of many trials remains poor. In Glasziou et al.'s study, $40-89 \%$ of the interventions were not replicable due to a poor description and in most studies, at least one Primary Outcome Measure was changed, introduced or omitted. ${ }^{11}$ In Yordanov et al.'s methodological review and simulation study of trials 
included in Cochrane reviews, $43 \%$ of the 1,286 studies identified had at least one domain at high risk of bias and 142 of a random sample of 200 of the aforementioned trials were confirmed as high risk. ${ }^{12}$ Secondly, "trialists" routinely pretend that uncertainty doesn't exist. We pick single point estimates for all of these parameters, create a design that would work well if all of those guesses happen to be true simultaneously (a very unlikely event) and then we put that design into a grant that we hope gets funded". ${ }^{13}$ As further highlighted by Lewis, "this approach leads to an increased risk of falsely negative or inconclusive results".

An even more fundamental issue is that effect sizes alone are not enough to facilitate the implementation of research findings in clinical practice or public health: "effect sizes do not provide policy makers with information on how an intervention might be replicated in their specific context, or whether trial outcomes will be reproduced". ${ }^{14}$ As Grant et al. highlight, one of the reasons why so much clinical research is ignored is because "there is not enough contextual information provided to transfer the results from the trial setting into other settings". ${ }^{15}$ A further problem is the common conflation of efficacy and effectiveness; demonstrating that a health technology 'works' (efficacy) does not necessarily mean that it can improve health at a population level (effectiveness). ${ }^{16}$

Another critique of the evidence-based paradigm relates to how evidence is synthesised and analysed. Trials with positive results are published in approximately four to five years, whilst trials with null or negative results take six to eight years to publish. ${ }^{17}$ As multiple trials are required for one systematic review, they become highly resource intensive. ${ }^{18}$ This contrasts with the often rapidly moving policy context where structures at a micro, meso and macro level (i.e. at the level of the clinician, the commissioner of services and at a Government level respectively) can change very quickly. As Gannan et al. highlight, "emerging issues require access to high-quality evidence in a timely manner to inform system and policy response". ${ }^{19}$

Another concern with the process is that many systematic review methodologies have a tendency to strip out the policy context. This has led some researchers to adopt a theoretical approach to help guide the process of the review and make sure key elements are retained, particularly where the intervention is complex. Implementation frameworks, such as the Knowledge-To-Action framework, ${ }^{20}$ and other methods (for example realist syntheses) explicitly seek to include and 
understand the role of context and how and why interventions or programmes work. ${ }^{21}$ We consider this to be critical. As Northridge \& Metcalf highlight, there is a "need to extract the core issues from the context in which they are embedded in order to better ensure that they are transferable across settings". ${ }^{22}$ Such insights highlight the value of shifting from the traditionally used binary question of effectiveness towards a more sophisticated explanation. ${ }^{23}$

Once evidence has been synthesised, the response by the evidence user can be idiosyncratic and these problems become magnified when interventions are introduced into complex social or organisational systems. ${ }^{24} \mathrm{~A}$ number of systemrelated challenges relate to this process and introduce variation that needs to be considered and managed. Such challenges refer to the variability and stability (and predictability) across and within organisations, the range of solutions applicable to any given problem, the multiple mechanisms involved, the differing ability of the individual/organisation to affect these mechanisms and the varying relationships between mechanisms and outcomes (in terms of linearity and impact). ${ }^{25}$ Equally, evidence is often "weighed-up" alongside other clinical factors and experiential knowledge can be privileged. ${ }^{26,27}$ As a result, the production of evidence in its own right is not sufficient per se to influence change. ${ }^{28}$ Decision-making is a process, not a one-off event, and relies on productive on-going relationships and the organisational context. ${ }^{29,30}$

\section{Producing change in population oral health?}

One of the key challenges relates to the relevance of the RCTs and the degree of their use to shape policy aiming to improve the population's oral health. There is evidence that outputs from trials have had a direct impact on public health policy. Recently, Chestnutt et al.'s 'Seal or Varnish' trial led to a near immediate cessation of a national sealant scheme across Wales in favour of a fluoride varnish scheme. They concluded that "in a community oral health programme utilising mobile dental clinics and targeted at children with high caries risk, the twice-yearly application of fluoride varnish resulted in caries prevention that is not significantly different from that obtained by applying and maintaining fissure sealants after 36 months" and that fluoride varnish was more cost-effective. ${ }^{31}$ Equally, Milsom et al.'s trial on dental screening programmes for school-aged children produced a policy change by the National Screening Committee in the United Kingdom (UK) and Innes et al.'s trial on

the Hall technique made a substantive impact on the management of child caries. ${ }^{32,33}$ 
However, this is in contrast with a number of trials whose results have had less impact to date..$^{34,35}$

As highlighted above, the use of the evidence-based paradigm can be applied without critical thought. At a population level, there are arguments for the inclusion of other study designs to augment the evaluation of dental public health programmes and health policies. ${ }^{36}$ The recent debate following the publication of the Cochrane review on the effectiveness of water fluoridation illustrates this point. This review was influenced by the exclusion of observational studies and concluded that "there is very little contemporary evidence, meeting the review's inclusion criteria". ${ }^{37}$ However, in their critique, Rugg-Gunn et al. argued that "with public health interventions [....] there are frequently no such trials because the highly complex practical, ethical and financial factors involved mean that RCTs are not feasible". ${ }^{38}$ They go on to argue that unlike individual clinical interventions, evidence has to be drawn from a wide variety of research designs to determine whether a complex public health intervention is cost effective. This approach was undertaken by the National Health and Medical Research Centre (NHMRC) in Australia, who reached a different conclusion: "the NHMRC strongly recommends community water fluoridation as a safe, effective and ethical way to help reduce tooth decay across the population". ${ }^{39}$

Antibiotic prophylaxis for infective endocarditis is another example. This was common-place in the UK until 2008, when the National Institute of Clinical Excellence's (NICE) stated that "antibiotic prophylaxis against infective endocarditis is not recommended for people undergoing dental procedures". ${ }^{40} \mathrm{NICE}$ relies heavily on evidence from clinical trials and evidence from other study designs downgraded; as such, it appeared 'locked into' a recommendation that was at odds with the international consensus. ${ }^{41}$ It also became at odds with a large observational study that demonstrated that the cessation of antibiotic prophylaxis (NICE guidance) had increased the risk of patients contracting infective endocarditis. ${ }^{42}$ In recognition of this confusion and yet without any further evidence, NICE changed its recommendation in 2016 to "antibiotic prophylaxis against infective endocarditis is not recommended routinely for people undergoing dental procedures", creating a great deal of confusion. ${ }^{43}$

The use of taxation for Sugar-Sweetened Beverages (SSBs) is another area where the uncritical adoption of the evidence-based paradigm is problematic. Empirically 
evaluating the impact of a 'sugar-tax' would require participants to be randomised to different price levels in any one country. This would be clearly unfeasible.

Furthermore, making cross-country comparisons would be highly resource intensive and a systematic review using multiple trials would be even more unlikely.

Quasi-experimental methodologies have been used to show reduction in the consumption of SSBs and increase in water consumption after implementing a sugar tax, ${ }^{44}$ while modelling studies have explored the potential impact of such an intervention on population health and the economy. ${ }^{45}$ In the absence of evidence from experimental evidence, a health care decision maker has to ask: which other types of information are suitable for timely and evidence-informed decision making? Health policies, particularly with regards to public health, often need to be formulated at a time point when the respective evidence base is still rather limited. ${ }^{46}$ And the traditional evidence-based model around RCTs does not fit well public health interventions that require strong theoretical underpinnings, wider methodological approaches and a focus on complex systems. ${ }^{47}$

\section{The application of theoretical approaches to help evidence use}

Psychological theory is increasingly being used to predict individual behaviour change and improve the adoption of evidence. ${ }^{48}$ These theories set out to understand the proximal determinants of behaviour including beliefs (cognitions), knowledge, and the attitudes and motivations that underlie an individual's behavioural intentions, and ultimately their behaviour. ${ }^{49,50}$ The underlying assumption is that understanding behaviour is enough to produce changes at scale. ${ }^{51}$ Such approaches have been used in dentistry in relation to adherence to guidelines for fissure sealants, ${ }^{52}$ intra-oral radiographs, ${ }^{53}$ caries management for children, ${ }^{54}$ and advising on oral health-related behaviours. ${ }^{55}$

To date, psychological theories have been shown to be important as they target behavioural drivers that are potentially amenable to change. ${ }^{56}$ Recent developments have also seen an attempt to synthesise these. The Theoretical Domains Framework (TDF) brings together a large number of psychological theories and constructs that have been found to influence health professional's behaviour. ${ }^{57,58}$ The 14 domains of the TDF include constructs such as, knowledge, skills, social/professional role and identity, and beliefs about capability. ${ }^{59}$ 
The TDF has also been applied to dentistry: antibiotic prescribing, ${ }^{60}$ caries management, ${ }^{61,62}$ and the application of fluoride varnish to children's teeth. ${ }^{63}$ However, there remains a lack of focus on the organisational context, including practice culture and other factors that can influence individual clinician's decision making. This is problematic because the implementation of evidence requires complex changes in clinical practice within complex health systems. These take place not because of individual's behavioural processes but through collective action enacted by teams within health care organisations. ${ }^{64}$ For example, dentists do not adopt evidence-based preventive care because of a lack of inertia, up-to-date knowledge or skills, but commonly because of practical (existing logistics of the dental practice), cultural (dentists perceptions of their patients and patients' motivations, values, co-operativeness) and economic (time constraints, financial risk, funding systems) barriers. ${ }^{65,66}$ Arguably, rather than targeting different levels for effective change - individual clinician (e.g. dentist, dental hygienist), health care unit or team (e.g. dental practice), health care organisation (e.g. National Health Service) - the system 'as a whole' needs to be considered. ${ }^{67}$

\section{What can implementation science offer?}

Given the persistent and often intractable challenges of evidence-based healthcare, there has been a growing interest in the study of implementation processes and approaches in order to unpack the 'black box'. Implementation research reinforces the assertion that evidence production does not naturally flow into evidence use. As highlighted above, people use tacit and collective knowledge to determine whether evidence is credible, and whether it fits with their experience and practice. ${ }^{27}$ Evidence users are not passive recipients and their practice is influenced by the context in which they work. Organisation features such as organisational slack, resources, the nature and quality of leadership, culture, and communication systems are all important. ${ }^{68}$

The evidence base suggests that there is more promise in approaches that are theoretically based, interactive and tailored. ${ }^{69}$ For example, there is growing support for the use of change agents in implementation processes. One such change agent is facilitation, where evidence is three times more likely to be adopted. ${ }^{70,71}$ Training lay workers as facilitators of quality improvement in Vietnam showed a significantly positive effect on neonatal mortality. ${ }^{72}$ Implementation frameworks are also important in the choice and development of interventions, for identifying appropriate outcomes, 
measures and variables of interest, and in guiding the evaluation of implementation processes and outcomes. These include the Promoting Action on Implementation in Health Services (PARIHS), Knowledge to Action, the Consolidated Framework for Implementation Research, and Normalisation Process Theory. These help to shift the thinking away from viewing the gap between evidence and practice as being a 'service problem', to one that acknowledges the importance of how knowledge is created. The idea that users and producers of evidence occupy two separate worlds has not been helpful in accelerating progress with the evidence-based practice agenda. As such there is increasing interest in the development of more collaborative type arrangements such as Collaborations for Leadership in Applied Health and Care in the UK. Here, the producers and users of evidence work together to create knowledge that solve service challenges in more co-productive ways.

\section{Discussion}

This paper has argued that an uncritical adherence to the evidence-based paradigm is not always feasible, desirable, or ethical for complex healthcare interventions. ${ }^{73}$ In addition, it has argued that evidence production is not enough to stimulate evidence use particularly highlighting the importance of carefully considering the theoretical underpinnings of change and the role of the context for implementation.

There are a number of pragmatic steps that could be taken when designing trials of complex interventions to approve adoption. These include thinking about implementation a priori and working with policy-makers, commissioners, public health officials, clinicians and the public at the beginning of the evidence generation process to ensure that the research agenda is co-produced. Factors associated with the context of a complex intervention should also be considered the earliest stage in the evaluation process, using theoretically informed feasibility and pilot studies. ${ }^{74}$ Theoretical frameworks should be used more prospectively as part of the trial design process for complex interventions (or other ex-post methodologies) ${ }^{75,76}$ Equally, process evaluations should be run in parallel alongside empirical evaluations of complex interventions in order to help understand 'the causal assumptions underpinning the intervention and ... how interventions work in practice' ${ }^{77}$ In addition, the use of Studies Within A Trial can help understand the best way to ensure adequate representation of those that are recruited. ${ }^{78}$ 
The standardisation of outcome measures used in trials of amenable population programmes to promote oral health would also be of real value. As highlighted by Kirkham, there is "growing recognition that insufficient attention has been paid to the outcomes measured in clinical trials, which need to be relevant to health service users and other people making choices about health care if the findings of research are to influence practice". ${ }^{79}$ In the past, the heterogeneity of outcome measures used by many trialists has made meta-analysis difficult and has added to research waste. By taking a co-produced approach to developing a Core Outcome Set (COS), this type of research waste can be reduced. ${ }^{91}$ This heterogeneity of outcomes measurement has also been a feature of oral health research and work to validate COSs (e.g. the current project between the World Dental Federation and the International Consortium for Health Outcomes Measurement) may inform the consistent selection of oral health outcomes for relevant interventions.

More thought should be given to the type of evidence that is assimilated in systematic reviews of large scale programmes to improve oral health, including the use of ex-post and ex-ante designs. Ex-post techniques typically evaluate the impact of an already implemented health policy programme and include a range of quasiexperimental methods including Instrumental Variables, Difference-in-Difference, panel data analyses using fixed or random effects, and Regression-DiscontinuityDesigns (see Listl et al.). ${ }^{80} \mathrm{~A}$ recent study used such an approach to evaluate the impact of a SSB tax in Mexico. The study showed a significant reduction in consumption, since its introduction in $2014 .^{81}$ In contrast, ex-ante techniques are designed to simulate the future response resulting from hypothetical interventions and to make comparisons with simulated alternative scenarios of interest to the decision maker. ${ }^{72}$ Ex-ante methods include structural modelling, agent-based modelling and micro-simulation and unlike the ex-post methods can help predict the short, mid and long-term health effects of an intervention. ${ }^{82,83}$ Such methodologies can provide very helpful information on the evaluation of policies and interventions that would otherwise not be rigorously evaluated as the standard RCT related methodologies are neither feasible nor suitable.

More attention should be paid to an understanding of context and attempts should be made not to throw away evidence during the assimilation process that could help describe this. Again, the use of theoretical frameworks and logic models to help guide the review process are key. ${ }^{84}$ Such approaches can "aid in the 
conceptualization of the review focus and illustrate hypothesized causal links, identify effect mediators or moderators, specify intermediate outcomes and potential harms, and justify a priori subgroup analyses when differential effects are anticipated". They can describe the system into which the intervention and context takes place (systembased logic model) or the processes and causal pathways that lead to the outcomes (process-orientated logic model). ${ }^{85}$ They can also help identify the most relevant inclusion criteria and clarify the interpretation of results for policy-relevant conclusions.

Finally, more thought should be given to the use of realist reviews and rapid realist reviews in the dental literature, which specifically account for context and try to understand the underlying programme theories ('what works for whom, why and in what circumstances'). These would help to provide a more nuanced understanding, augment and broaden a triangulation process with existing evidence-based approaches for large-scale change in population oral health. ${ }^{86}$ Moving towards the aforementioned suggestions presents a major but welcome challenge for oral health research as it would enrich the evaluation methodological scope and facilitate the wider use and implementation of appropriate evidence into clinical practice and public health, thereby having potential for improving the oral health of the population.

Financial disclosure: there are no known commercial or financial conflicts of interest or funding sources for any of the authors listed above. 


\section{References}

${ }^{1}$ Kassebaum NJ, Smith AG, Bernabé E, Fleming TD, Reynolds AE, Vos T, Murray CJ, Marcenes W. Global, regional, and national prevalence, incidence, and disabilityadjusted life years for oral conditions for 195 countries, 1990-2015: a systematic analysis for the global burden of diseases, injuries, and risk factors. J Dent Res. 2017;96(4):380-387.

${ }^{2}$ Listl S, Galloway J, Mossey PA, Marcenes W. Global economic impact of dental diseases. J Dent Res. 2015;94(10):1355-1361.

${ }^{3}$ Righolt AJ, Jevdjevic M, Marcenes W, Listl S. Global-, Regional-, and CountryLevel Economic Impacts of Dental Diseases in 2015. J Dent Res. 2018;97(5): 501507.

${ }^{4}$ Greyson DL, Cunningham C, Morgan S. Information behaviour of Canadian pharmaceutical policy makers. Health Info Libr J. 2012;29:16-27. doi:10.1111/j.14711842.2011.00969.x.

${ }^{5}$ Zardo P, Collie A. Type, frequency and purpose of information used to inform public health policy and program decision-making. BMC Public Health. 2015;15:381. doi:10.1186/s12889-015-1581-0.

${ }^{6}$ Greenhalgh T, Fahy N. Research impact in the community-based health sciences: an analysis of 162 case studies from the 2014 UK research excellence framework. BMC Med. 2015;13:232. doi:10.1186/s12916-015-0467-4.

${ }^{7}$ Sackett DL, Rosenberg WMC, Gray JAM, Haynes RB, Richardson WS. Evidence based medicine: what it is and what it isn't. BMJ. 1996; 312 doi:

http://dx.doi.org/10.1136/bmj.312.7023.71

8 Innes NPT, Schwendicke F, Lamont T. How do we create, and improve, the evidence base? Br Dent J. 2016;220:651-655. doi:10.1038/sj.bdj.2016.451. ${ }^{9}$ Davies HTO, Powell AE, Nutley SM. Mobilising knowledge to improve UK health care: learning from other countries and other sectors - a multi-method mapping study. Health Serv Deliv Res. 2015; 3.

${ }^{10}$ Medical Research Council. A framework for development and evaluation of RCTs for complex interventions to improve health. 2000. Available at: https://www.mrc.ac.uk/documents/pdf/rcts-for-complex-interventions-to- improvehealth/. Downloaded 27 March 2017.

${ }^{11}$ Glasziou P, Altman DG, Bossuyt P, Boutron I, Clarke M, Julious S, Michie S, Moher D, Wager E. Reducing waste from incomplete or unusable reports of 
biomedical research. Lancet. 2014 Jan 18;383(9913):267-76. doi: 10.1016/S01406736(13)62228-X.

12 Yordanov Y, Dechartres A, Porcher R, Boutron I, Altman DG, Ravaud P. Avoidable waste of research related to inadequate methods in clinical trials. BMJ.

2015;24(350):h809. doi: 10.1136/bmj.h809.

${ }^{13}$ Lewis RJ. The pragmatic clinical trial in a learning health care system. Clinical Trials. 2016;13(5):484-492.

${ }^{14}$ Moore GF, Audrey S, Barker M et al. Process evaluation of complex interventions: Medical Research Council guidance. BMJ. 2015;350:h1258. doi: 10.1136/bmj.h1258. ${ }^{15}$ Grant A, Treweek S \& Wells M. Why is so much clinical research ignored and what can we do about it?, Br J Hosp Med. 2016;77(Supplement 10):554-555.

${ }^{16}$ Barratt H, Campbell M, Moore L, Zwarenstein M, Bower P. Randomised controlled trials of complex interventions and large-scale transformation of services. Health Serv Deliv Res. 2016;4:19-36.

${ }^{17}$ Hopewell S, Clarke MJ, Stewart L, Tierney J. Time to publication for results of clinical trials. Cochrane Database of Systematic Reviews 2007, Issue 2. Art. No.: MR000011. DOI: 10.1002/14651858.MR000011.pub2.

${ }^{18}$ Lehoux P, Tailliez S, Denis JL, Hivon M: Redefining health technology assessment in Canada: diversification of products and contextualization of findings. Int J Technol Assess Health Care. 2004;20:325-336.

${ }^{19}$ Ganann R, Ciliska D, Thomas H. Expediting systematic reviews: methods and implications of rapid reviews. Implement Sci. 2010;5:56.

20 Graham I, Logan J, Harrison M, Straus S, Tetroe J, Caswell W, Robinson N: Lost in knowledge translation: time for a map? J Contin Educ Health Prof. 2006;26:13-24. 10.1002/chp.47.

${ }^{21}$ Wong G, Greenhalgh T, Westhorp G, Buckingham J, Pawson R. RAMESES publication standards: realist syntheses. BMC Medicine.

2013;11(21):https://doi.org/10.1186/1741-7015-11-21

${ }^{22}$ Northridge ME, Metcalf SS. Enhancing implementation science by applying best principles of systems science. Health Res Policy Sys. 2016;14:74. DOI 10.1186/s12961-016-0146-8.

${ }^{23}$ Bate P, Robert G, Fulop N, Øvretveit J, Dixon-Woods M. Perspectives on Context. London: The Health Foundation; 2014.

${ }^{24}$ Greenhalgh T, Wieringa S. Is it time to drop the 'knowledge translation' metaphor? A critical literature review. J Royal Soc Med. 2011;104:501-509. 
${ }^{25}$ Hasan \& Kazlauskas. Cynefin framework: putting complexity into perspective. In., Being Practical with Theory.

${ }^{26}$ Rycroft-Malone J, Harvey G, Seers K, Kitson A, McCormack B, Titchen A. An exploration of the factors that influence the implementation of evidence into practice. J Clin Nurs 2004;13(8):913-924.

${ }^{27}$ Dopson S, FitzGerald L, Ferlie E, Gabbay J, Locock L. No magic targets! Changing clinical practice to become more evidence based. Health Care Man Rev. 2002;27:35-47.

${ }^{28}$ Rycroft-Malone J, Burton CR, Wilkinson J, Harvey G, McCormack B, Baker R, Dopson S, Graham ID, Staniszewska S, Thompson C, Ariss S, Melville-Richards L, Williams L. Collective action for implementation: a realist evaluation of organisational collaboration in healthcare. Implement Sci. 2016;11:17 DOI 10.1186/s13012-0160380-z.

${ }^{29}$ Currie G, Waring J, Finn R. The limits of knowledge management for UK public services modernization: the case of patient safety and service quality. Pub Admin. 2008;86(2):363-385.

${ }^{30}$ Salter KL, \& Kothari A. Knowledge 'Translation' as social learning: negotiating the uptake of research-based knowledge in practice. BMC Med Educ. 2016;16.

${ }^{31}$ Chestnutt IG, Hutchings S, Playle S, Morgan-Trimmer S, Fitzsimmons D, Aawar N, Angel L, Derrick S, Drew C, Hoddell C, Hood K, Humphreys I, Kirby N, Lau TMN, Lisles C, Morgan MZ, Murphy S, Nuttall J, Onishchenko K, Phillips C, Pickles T, Scoble C, Townson J, Withers B, Chadwick BL. Seal or Varnish? A randomised controlled trial to determine the relative cost and effectiveness of pit and fissure sealant and fluoride varnish in preventing dental decay. Health Tech Assess. 2017;21(21):1-256. DOI 10.3310/hta21210.

${ }^{32}$ Milsom K, Blinkhorn A, Worthington $\mathrm{H}$, Threlfall A, Buchanan K, Kearney-Mitchell P, Tickle M. The Effectiveness of School Dental Screening: a Cluster-randomized Control Trial. J Dent Res. 2006;85(10):924-928.

${ }^{33}$ Innes NP1, Evans DJ, Stirrups DR. The Hall Technique; a randomized controlled clinical trial of a novel method of managing carious primary molars in general dental practice: acceptability of the technique and outcomes at 23 months. BMC Oral Health. 2007 Dec 20;7:18.

${ }^{34}$ Tickle M, O'Neill C, Donaldson M, Birch S, Noble S, Killough S, Murphy L, Greer M, Brodison J, Verghis R, Worthington HV. A randomised controlled trial to measure the effects and costs of a dental caries prevention regime for young children attending 
primary care dental services: the Northern Ireland Caries Prevention In Practice (NIC-PIP) trial. Health Tech Assess. 2016;20(71):1-96. doi: 10.3310/hta20710. ${ }^{35}$ Milsom KM, Blinkhorn AS, Walsh T, Worthington HV, Kearney-Mitchell P, Whitehead $\mathrm{H}$, Tickle M. A cluster-randomized controlled trial: fluoride varnish in school children. J Dent Res. 2011;90(11):1306-11. doi: 10.1177/0022034511422063. ${ }^{36}$ Victora CG, Habicht JP, Bryce J. Evidence-based public health: moving beyond randomized trials. Am J Public Health. 2004;94(3):400-5.

${ }^{37}$ Iheozor-Ejiofor Z, Worthington HV, Walsh T, O'Malley L, Clarkson JE, Macey R, Alam R, Tugwell P, Welch V, Glenny A. Water fluoridation for the prevention of dental caries. Cochrane Database of Systematic Reviews. 2015, Issue 6. Art. No.: CD010856. DOI: 10.1002/14651858.CD010856.pub2

${ }^{38}$ Rugg-Gunn AJ, Spencer AJ, Whelton HP, Jones C, Beal JF, Castle P, Cooney PV, Johnson J, Kelly MP, Lennon MA, McGinley J, O’Mullane D, Sgan-Cohen HD, Sharma PP, Thomson WM, Woodward SM, Zusman SP. Critique of the review of 'Water fluoridation for the prevention of dental caries' published by the Cochrane Collaboration in 2015. Br Dent J. 2016;220:335-340.

${ }^{39}$ National Health and Medical Research Council (NHMRC) 2017, Information paper - Water fluoridation: dental and other human health outcomes, report prepared by the Clinical Trials Centre at University of Sydney, NHMRC; Canberra.

40 Thornhill MH, Dayer M, Lockhart PB, McGurk M, Shanson D, Prendergast B, Chambers JB. Guidelines on prophylaxis to prevent infective endocarditis. Br Dent J. 2016;220:51-56.

${ }^{41}$ Habib G, Hoen B, Tornos P et al. Guidelines on the prevention, diagnosis, and treatment of infective endocarditis (new version 2009): the Task Force on the Prevention, Diagnosis, and Treatment of Infective Endocarditis of the European Society of Cardiology (ESC). Endorsed by the European Society of Clinical Microbiology and Infectious Diseases (ESCMID) and the International Society of Chemotherapy (ISC) for Infection and Cancer. Eur Heart J. 2009;30:2369-2413. 42 Dayer MJ, Jones S, Prendergast B, Baddour LM, Lockhart PB, Thornhill MH. Incidence of infective endocarditis in England, 2000-13: a secular trend, interrupted time-series analysis. Lancet. 2015;385:1219-28.

43 Thornhill MH, Dayer M, Lockhart PB, McGurk M, Shanson D, Prendergast B, Chambers JB. A change in the NICE guidelines on antibiotic prophylaxis. Brit Dent $\mathrm{J}$. 2016;221:112-114. 
${ }^{44}$ Colchero MA, Molina M, Guerrero-López CM. After Mexico Implemented a Tax, Purchases of Sugar-Sweetened Beverages Decreased and Water Increased:

Difference by Place of Residence, Household Composition, and Income Level. J Nutr. 2017;147(8):1552-1557.

${ }^{45}$ Briggs ADM, Mytton OT, Kehlbacher A, Tiffin R, Elhussein A, Rayner M, Jebb SA, Blakely T, Scarborough P. Health impact assessment of the UK soft drinks industry levy: a comparative risk assessment modelling study. Lancet Public Health. 2017;2(1):e15-e22.

${ }^{46}$ Zucchelli, E., Jones, A. M., \& Rice, N. (2012). The evaluation of health policies through dynamic microsimulation methods. Int J Microsim. 2012;5(1):2-20.

${ }^{47}$ Rutter H, Savona N, Glonti K, Bibby J, Cummins S, Finegood DT et al. The need for a complex systems model of evidence for public health. Lancet. 2017;390:26022604.

${ }^{48}$ Eccles MP, Grimshaw J, Walker A, Johnston M, Pitts N. Changing the behaviour of healthcare professionals: the use of theory in promoting the uptake of research findings. J Clin Epidem. 2005;58:107-112.

${ }^{49}$ Eccles MP, Grimshaw JM, MacLennan G, Bonetti D, Glidewell L, Pitts NB, Steen N, Thomas R, Walker A, Johnston M. Explaining clinical behaviours using multiple theoretical models. Implement Sci. 2012;7:99.

50 Godin G, Belanger-Gravel A, Eccles M, Grimshaw J. Healthcare professionals' intentions and behaviours: a systematic review of studies based on social cognitive theories. Implement Sci. 2008;3:36.

${ }^{51}$ Michie S, Fixsen D, Grimshaw JM, Eccles MP. Specifying and reporting complex behaviour change interventions: the need for a scientific method. Implement Sci. 2009;4:doi:10.1186/1748-5908-1184-1140.

52 Bonetti D, Johnston M, Clarkson J et al. Applying psychological theories to evidence-based clinical practice: Identifying factors predictive of placing fissure sealants. Implement Sci. 2010;5:25.

${ }^{53}$ Bonetti DL, Pitts N, Eccles M et al. Applying psychological theory to evidencebased clinical practice: identifying factors predictive of taking intra-oral radiographs. Soc Sci Med 2006;63:1889-1899.

${ }^{54}$ Bonetti DL, Johnston M, Turner S, Clarkson J. Applying multiple models to predict clinicians' behavioural intention and objective behaviour when managing children's teeth. Psychol Health. 2009;24:843-860. 
55 Yusuf H, Kolliakou A, Ntouva A, Murphy M, Newton T, Tsakos G, Watt RG.

Predictors of dentists' behaviours in delivering prevention in primary dental care in England: using the theory of planned behaviour. Br Dent J. 2016;16:44.

${ }^{56}$ Asimakopoulou K, Newton JT. The contributions of behaviour change science towards dental public health practice: a new paradigm. Community Dent Oral Epidemiol. 2015;43:2-8.

${ }^{57}$ Davis R, Campbell R, Hildon Z, Hobbs L, Michie S. Theories of behaviour and behaviour change across the social and behavioural sciences: a scoping review. Health Psychol Rev. 2015;9:323-344.

${ }^{58}$ Michie S, Richardson M, Johnston M, Abraham C, Francis J, Hardeman W et al. The behaviour change taxonomy ( $v 1)$ of 93 hierarchically clustered techniques: building an international consensus for the reporting of behaviour change interventions. Ann Behav Med. 2013;46:81-95.

${ }^{59}$ Cane J, O'Connor D, Michie S. Validation of the theoretical domains framework for use in behaviour change and implementation research. Implement Sci. 2012;7:37. ${ }^{60}$ Newlands R, Duncan EM, Prior M, Elouafkaoui P, Elders A, Young L, Clarkson JE, Ramsay CR. Barriers and facilitators of evidence-based management of patients with bacterial infections among general dental practitioners: a theory-informed interview study. Implement Sci. 2016;11:11.

${ }^{61}$ Schwendicke F, Foster Page LA, Smith LA, Fontana M, Thomson Wm, Baker SR. To fill or not to fill: a qualitative cross-country study on dentists' decisions in managing non-cavitated proximal caries lesions. Implement Sci. 2018;13:54. 62 Templeton AR, Young L, Bish A, Gnich W, Casie H, Treweek S, Bonetti D, Stirling D, Macpherson L, McCann S, Clarkson J, Ramsay C. Patient-, organisation-, and system-level barriers and facilitators to preventative oral health care: a convergent mixed-methods study in primary dental care. Implement Sci. 2016;11:5. ${ }^{63}$ Gnich W, Bonetti D, Sherriff A, Sharma S, Conway DI, Macpherson LM. Use of the theoretical domains framework to further understanding of what influences application of fluoride varnish to children's teeth: a national survey of general dental practitioners in Scotland. Community Dent Oral Epidemiol. 2015;43: 272-81. 64 Johnson MJ, May CR. Promoting professional behaviour change in healthcare: what interventions work, and why? A theory-led overview of systematic reviews. BMJ Open. 2015;5:e008592. 
65 Sbaraini A, Carter SM, Evans RW, Blinkhorn A. How do dentists and their teams incorporate evidence about preventative care? An empirical study. Community Dent Oral Epi. 2013;41:401-414.

${ }^{66}$ Brocklehurst PR, Price J, Glenny AM, Tickle M, Birch S, Mertz E, Grytten J. The effect of different methods of remuneration on the behaviour of primary care dentists. Cochrane Database of Systematic Reviews 2013, Issue 11. Art. No.: CD009853. DOI: 10.1002/14651858.CD009853.pub2.

${ }^{67}$ Chandler J, Rycroft-Malone J, Hawkes C, Noyes J. Application of simplified Complexity Theory concepts for healthcare social systems to explain the implementation of evidence into practice. J Adv Nurs. 2016;72:461-480.

68 Damschroder L, Lowery J C. Evaluation of a large-scale weight management program using the consolidated framework for implementation research (CFIR). Implement Sci. 2013;8:51.

69 Baker R, Camosso-Stefinovic J, Gillies C, Shaw EJ, Cheater F, Flottorp S, Robertson N: Tailored interventions to overcome identified barriers to change: effects on professional practice and health care outcomes. Cochrane Database Syst Rev. 2010, 10.1002/14651858.CD005470.pub2/

70 Baskerville NB, Liddy C, Hogg W. Systematic review and meta-analysis of practice facilitation within primary care settings. Annals of Family Medicine. 2102;10(1):63-74.

${ }^{71}$ McCormack B, Rycroft-Malone J, DeCorby K, Hutchinson AM, Bucknall T, Kent B, Schultz A, Snelgrove-Clarke E, Stetler C, Titler M, Wallin L, Wilson V. A realist review of interventions and strategies to promote evidence-informed healthcare: a focus on change agency. Implement Sci. 2013;8(1):107.

72 Persson LA, Nga NT, Malqvist M, Thi Phuong Hoa D, Eriksson L, Wallin L, Selling K, Huy TQ, Duc DM, Tiep TV, Thi Thu Thuy V, Ewald U. Effect of Facilitation of Local Maternal-and-Newborn Stakeholder Groups on Neonatal Mortality: Cluster-

Randomized Controlled Trial. PLoS Med. 2013;10(5):e1001445.

${ }^{73}$ Alla K, Hall WD, Whiteford HA, Head BW, Meurk CS. How do we define the policy impact of public health research? A systematic review. Health Res Policy Systems. 2017;15:84. doi 10.1186/s12961-017-0247-z.

${ }^{74}$ Eldridge SM, Lancaster GA, Campbell MJ, Thabane L, Hopewell S, Coleman CL. Defining feasibility and pilot studies in preparation for randomised controlled trials:

Development of a conceptual framework. PLoS ONE. 2016;11: e0150205. doi: 10.1371/journal. pone.0150205. 
${ }^{75}$ Rycroft-Malone J, Seers K, Chandler J et al. The role of evidence, context, and facilitation in an implementation trial: implications for the development of the PARIHS framework. Implement Sci. 2013;8:28.

${ }^{76}$ Murray E, Treweek S, Pope $\mathrm{C}$ et al. Normalisation process theory: a framework for developing, evaluating and implementing complex interventions. BMC Med. 2010;8:63.

77 Moore G F, Audrey S, Barker M et al. Process evaluation of complex interventions: Medical Research Council guidance. BMJ 2015;350:h1258. doi: 10.1136/bmj.h1258. 78 Treweek S, Bevan S, Bower P, Campbell M, Christie J, Clarke M, Collett C, Cotton S, Devane D, El Feky A, Flemyng E, Galvin S, Gardner H, Gillies K, Jansen J, Littleford R, Parker A, Ramsay C, Restrup L, Sullivan F, Torgerson D, Tremain L, Westmore M, Williamson PR. Trial Forge Guidance 1: what is a Study Within A Trial (SWAT)? Trials. 2018;19:139. doi.org/10.1186/s13063-018-2535-5.

${ }^{79}$ Kirkham JJ, Gorst S, Altman DG, Blazeby JM, Clarke M, et al. (2016) Core Outcome Set-Standards for Reporting: The COS-STAR Statement. PLOS Medicine. 2016;13(10): e1002148. https://doi.org/10.1371/journal.pmed.1002148

${ }^{80}$ Listl S, Jürges H, Watt RG. Causal inference from observational data. Community Dent Oral Epidemiol. 2016;44(5):409-15.

${ }^{81}$ Colchero M Arantxa, Popkin Barry M, Rivera Juan A, Ng Shu Wen. Beverage purchases from stores in Mexico under the excise tax on sugar sweetened beverages: observational study. BMJ. 2016;352:h6704.

82 Wolpin KI. Ex Ante Policy Evaluation, Structural Estimation, and Model Selection. American Economic Review. 2007;97(2):48-52.

${ }^{83}$ Bourguignon F, Spadaro A. Microsimulation as a tool for evaluating redistribution policies. Journal of Economic Inequality. 2006;4(1):77-106.

${ }^{84}$ Anderson LM, Petticrew M, Rehfuess E, Armstrong R, Ueffing E, Baker P, Francis $D$, Tugwell $P$. Using logic models to capture complexity in systematic reviews.

Research Synthesis Methods. 2011;2(1):33-42. doi.org/10.1002/jrsm.32 ${ }^{85}$ Rohwer A, Pfadenhauer L, Burns J, Brereton L, Gerhardus A, Booth A, Oortwijn W, Rehfuess E. Logic models help make sense of complexity in systematic reviews and health technology assessments. J Clin Epidemiol. 2017;83:37-47.

${ }^{86}$ Goodwin T, Brocklehurst PR, Williams L, Hall E. How, and why, does capitation affect General Dental Practitioners' behaviour? A rapid realist review. Brit J Healthcare Management 2018 (accepted). 